\title{
Improving Hospital Utilization and Outcomes: Health Economics at the Community Level
}

\author{
Ronald Lagoe*, Shelly Littau \\ Hospital Executive Council, Syracuse, USA \\ Email: hospexcl@cnymail.com
}

Received 29 January 2014; revised 4 March 2014; accepted 12 March 2014

Copyright (C) 2014 by authors and Scientific Research Publishing Inc.

This work is licensed under the Creative Commons Attribution International License (CC BY). http://creativecommons.org/licenses/by/4.0/

(c) (i) Open Access

\section{Abstract}

This study reviewed efforts to improve health care efficiency at the community level from the perspective of the financial impact on provider organizations. It focused on utilization and outcomes programs that address this objective in the metropolitan area of Syracuse, New York and their implications for health economics. The study demonstrated that a range of length of stay initiatives, including programs addressing length of stay reduction between hospitals and nursing homes produced a savings of $\$ 12,448,300$ - $\$ 31,232,900$ over a fifteen-year period. These efforts involved community wide costs of $\$ 3,128,125-\$ 4,144,025$. The study also demonstrated that efforts to reduce inpatient hospital complications produced a savings of between $\$ 1,622,400$ $\$ 3,623,400$ over a four-year period. These efforts involved community wide costs of $\$ 739,200$. The study suggested that these savings were enhanced through community wide initiatives that enabled hospitals to save expenses associated with data development and program implementation.

\section{Keywords}

Hospitalization; Quality of Care; Health Care Costs

\section{Introduction}

In many western nations, the need for improved efficiency and outcomes in the delivery of health care is increasing [1] [2]. This need is being stimulated by increases in health care expenses for major payers, by the continued impact of increasing service volumes on these expenses, and by greater recognition of the linkages between

\footnotetext{
*Corresponding author.
} 
increased efficiency and outcomes [3]-[5].

The need for cost constraints among major health payers is well documented. Although the growth of health care expenses has slowed in recent years, the levels of these expenses remain high [6]. In this situation, the federal government has resorted to administrative "productivity adjustments", including a number of penalties for provider inefficiencies and adverse outcomes, to generate funds from health care providers to sustain the Trust Fund [7]. At the same time, rising Medicaid expenses continue to exert major pressure on state and federal budgets. Health insurance costs are also challenging the viability of many private businesses.

Against this background, the reimbursement of health care expenses in most nations continues to be based on service volumes. In the United States, many hospitals are attempting to cover financial needs by generating increased inpatient and emergency department volumes, physician practices are working to expand visits, and nursing homes are attempting to maximize patient days [8] [9]. It appears that, in some communities, these providers are relying on increased service volumes to pay for increases in routine expenses such as staff salaries, pharmaceutical costs, and capital expenses.

In recent years, however, interest has focused on the connection between expenses and outcomes. Studies have demonstrated that adverse outcomes such as inpatient hospital complications and readmissions are responsible for substantial health care expenditures, at the patient specific and aggregate levels [10]-[12]. This research has been associated with the development of provider initiatives and resources to improve health care outcomes [13]-[18].

This study reviewed efforts to improve efficiency with health care volume and outcomes at the community level from the perspective of the economic and financial impact on provider organizations. It focused on programs that addressed this objective in a small metropolitan area within the United States through community wide hospital initiatives and their implications for health economics.

\section{Population and Methods}

This study evaluated the financial impact of a series of hospital efforts to constrain utilization and related expenses in the metropolitan area of Syracuse, New York. This area includes three acute hospitals (2012 acute care discharges in parentheses), Crouse Hospital $(24,358)$, St. Joseph’s Hospital Health Center $(28,029)$, and Upstate University Hospital $(28,553)$.

Historically, the Syracuse hospitals have worked together to improve the efficiency of care in the community through their collaborative planning organization, the Hospital Executive Council. These efforts have included the ongoing exchange of provider specific data and the development of specific programs to improve utilization and outcomes [19] [20]. The study focused on efforts to improve provider efficiency through two community wide initiatives.

\subsection{Utilization Efficiency — Length of Stay Reduction}

The initial component of this study focused on community wide programs of the Syracuse hospitals to reduce inpatient lengths of stay. It involved utilization changes and provider expenses avoided, as well as costs associated with these programs.

In order to identify provider expenses avoided, the study identified reductions in hospital stays for adult medicine and adult surgery that occurred in the combined Syracuse hospitals during the 15-year period between 1997 and 2012. The savings in inpatient lengths of stay were quantified as reductions in numbers of patient days for the two services. The same information was developed for discharges to long term care services, the largest source of excess days in the Syracuse hospitals.

The analysis also included estimates of the expenses saved through length of stay reduction in the Syracuse hospitals through reduction of stays for adult medicine and adult surgery in the combined Syracuse hospitals. These estimates were developed for all medical-surgical inpatients and for those discharged to long term care services. These estimates were based on the costs of patient days late in hospital stays, because the process did not affect utilization of intensive care or surgical services that typically occur early in hospitalization.

The study also identified estimated costs of the community wide programs that addressed these changes. Most of the reductions in hospital lengths of stay that occurred in the Syracuse hospitals between 1997 and 2012 were associated with long term care services. During this period, the hospitals developed community wide programs to address lengths of stay for discharges to nursing homes and home care through the Hospital Executive Council.

The largest initiative has been the Difficult to Place Program, a mechanism for sharing information among 
hospitals, nursing homes, and home health agencies concerning acute care patients who experience obstacles to admission to long term care services. These patients are identified by each of the Syracuse hospitals based on their specific experience in transferring patients. Lists of the patients, with names encrypted, are distributed by electronic mail through the hospitals and the Hospital Executive Council to nursing homes and home health agencies in the Central New York region. The program has also included monthly distribution of summary tables including numbers and rates of difficult to place admissions by facility to all hospitals and nursing homes in the community by the Council [21].

Length of stay reduction initiatives also include the Subacute Programs, a collection of projects that address specific services required by hospital patients who have experienced extended stays waiting for long term care services. These programs have addressed the need for intravenous medications, specific high cost oral medications, extensive wound care, bariatric care, and medical transportation. They have involved the distribution of program development funds through a community wide pool of funding administered by the Hospital Executive Council to expedite placement in long term care for patients who require these services [22].

Length of stay reduction in the Syracuse hospitals was also supported by monthly data for adult medicine and adult surgery institution specific stays compared with severity adjusted national averages. These comparisons were based on the All Patients Refined Diagnosis Related Group system developed by $3 \mathrm{M}^{\mathrm{TM}}$ Health Information Services. Drill downs based on these data by diagnosis, procedure, discharge status, physician, nursing unit, and other classifications were also available from the Council [23]. In these comparisons, differences between hospital stays and national averages were translated into patient days.

This study included cost estimates for the Difficult to Place Program, the Subacute Programs, and the distribution of severity adjusted length of stay data carried out by the Syracuse hospitals and the Hospital Executive Council. These estimated expenses were compared with the costs of the hospital patient days eliminated through this process.

\subsection{Outcomes-Reduction of Hospital Inpatient Complications}

The second component of the study involved a community wide effort to improve efficiency through reduction of inpatient hospital complications. These adverse outcomes that develop after inpatient admission have been identified as a source of excess hospitalization and related expenses in the community.

The study identified changes in numbers and rates of inpatient hospital complications through use of the Potentially Preventable Complications software developed by 3M${ }^{\mathrm{TM}}$ Health Information Systems. This tool employs administrative hospital data that contains the present on admissions indicator to identify diagnoses that developed after inpatient admission. The software also identifies complication rates per 1000 discharges. In the original version, the PPC software provides this information at the aggregate level and for 35 specific complications that involve medicine, surgery, and obstetrics [11] [24] [25].

In order to estimate expenses saved through reduction of inpatient complications, the PPC software was used to evaluate outcomes for two of the Syracuse hospitals, St. Joseph's Hospital Health Center and Crouse Hospital, between 2009 and 2012. Changes in total complications, as well as complications for pneumonia and urinary tract infections, the categories with the largest volumes for adult medicine and adult surgery, were identified.

In order to estimate changes in expenses that resulted from variations in complications, differences in patient days were employed as they were in the length of stay analysis. Differences in hospital mean stays between adult medicine and surgery inpatients and the populations with medicine and surgery complications, pneumonia complications, and urinary tract infection were used to estimate numbers of inpatient days avoided through reduction of hospital complications. These estimates were used to project expenses reduced through the initiatives.

The programs implemented to reduce inpatient complications were developed by the Syracuse hospitals and the Hospital Executive Council as part of a partnership with $3 \mathrm{M}^{\mathrm{TM}}$ Health Information Systems. The Potentially Preventable Complications software was provided to the hospitals and the Council by $3 \mathrm{M}^{\mathrm{TM}} \mathrm{HIS}$ in exchange for data developed through its use. The project was initiated in the fourth quarter of 2008 and continued through 2012.

The complications reduction program in Syracuse involved a combination of activities by the Hospital Executive Council and the participating Syracuse hospitals. Under this program, the Council was responsible for coordination and data development, while the hospitals were responsible for implementing interventions.

At the community wide level, the Council was responsible for producing PPC data, including frequencies and rates per 1000 discharges, at monthly and quarterly intervals for specific complications that were the objects of 
programs within the hospitals. These efforts included high volume complications such as pneumonia and urinary tract infection, as well as some low volume complications such as clostridium difficile colitis and decubitus ulcer.

Within each of the participating hospitals, staff was assigned to planning and implementing interventions to address complications, as well as evaluating the impact of this process in cooperation with the Hospital Executive Council. The planning process included review of patient specific medical records data in conjunction with the administrative data produced by the PPC software. It focused on identification and implementation of interventions to reduce complications with the nursing staff at St. Joseph's Hospital Health Center and the physician medical staff at Crouse Hospital.

\section{Results}

\section{Utilization Efficiency—Length of Stay Reduction}

Changes in adult medicine and adult surgery lengths of stay in the Syracuse hospitals and related utilization that occurred between 1997 and 2012 are summarized in Table 1.

Between 1997 and 2012, the combined hospitals generated a reduction in the mean length of stay for adult medicine from 6.33 to 5.12 days, resulting in the elimination for 30,369 inpatient days or an average daily census of 83.2 patients. During the same period, the hospitals generated a reduction in the mean length of stay for adult surgery patients from 7.33 to 6.05 days, resulting in the elimination of 26,023 patient days or an average daily census of 71.3 patients.

Since 1997, length of stay reduction initiatives developed by the hospitals collectively have involved discharges to long term care services. These patient populations have generated the largest numbers of excess hospital inpatient days, compared with national averages for adult medical and surgical patients with the same severity of illness as those in the Syracuse hospitals [22].

The data in Table 1 demonstrated that between 1997 and 2012, the number of excess adult medicine patient days resulting from discharges to nursing homes and home care declined by 21,347, a reduction in the average daily

Table 1. Hospital mean lengths of stay by discharge status Syracuse hospitals 1997, 2012.

\begin{tabular}{|c|c|c|c|c|c|c|}
\hline & \multirow{2}{*}{$\begin{array}{c}\text { Number of } \\
\text { Discharges } 1997\end{array}$} & \multicolumn{2}{|c|}{ Mean Length of Stay } & \multirow{2}{*}{$\begin{array}{l}\text { Length of Stay } \\
\text { Difference }\end{array}$} & \multirow{2}{*}{$\begin{array}{l}\text { Patient Days } \\
\text { Difference }\end{array}$} & \multirow{2}{*}{$\begin{array}{l}\text { Average Daily } \\
\text { Census Difference }\end{array}$} \\
\hline & & 1997 & 2012 & & & \\
\hline \multicolumn{7}{|l|}{ Adult Medicine } \\
\hline Self Care & 16,144 & 4.43 & 3.62 & 0.81 & 13076.64 & 35.73 \\
\hline Home Care & 4915 & 7.99 & 6.22 & 1.77 & 8699.55 & 23.77 \\
\hline Nursing Home & 2060 & 14.42 & 8.28 & 6.14 & 12648.40 & 34.56 \\
\hline Deaths & 1200 & 12.34 & 7.98 & 4.36 & 5232.00 & 14.30 \\
\hline Transfers & 780 & 4.50 & 5.24 & -0.74 & -577.20 & -1.58 \\
\hline Total & 25,099 & 6.33 & 5.12 & 1.21 & 30369.79 & 82.98 \\
\hline \multicolumn{7}{|l|}{ Adult Surgery } \\
\hline Self Care & 14,487 & 4.96 & 3.39 & 1.57 & 22744.59 & 62.14 \\
\hline Home Care & 3944 & 10.45 & 7.34 & 3.11 & 12265.84 & 33.51 \\
\hline Nursing Home & 1337 & 17.56 & 10.29 & 7.27 & 9719.99 & 26.56 \\
\hline Deaths & 461 & 23.30 & 21.42 & 1.88 & 866.68 & 2.37 \\
\hline Transfers & 102 & 16.83 & 11.70 & 5.13 & 523.26 & 1.43 \\
\hline Total & 20,331 & 7.33 & 6.05 & 1.28 & 26023.68 & 71.10 \\
\hline
\end{tabular}

Data exclude rehabilitation. Sources: New York Statewide Planning and Research Cooperative System (SPARCS) (1997 utilization data); Crouse Hospital; St. Joseph’s Hospital Health Center; and Upstate University Hospital (2012 utilization data). 
census of 58.5 patients. The data also demonstrated that, during the same period, the number of excess adult surgery patient days for discharges to nursing homes and home care declined by 21,985, a reduction in the average daily census of 60.2 patients.

The first component of the analysis also involved identification of financial benefits and costs of the length of stay reduction programs in the Syracuse hospitals. Related data are summarized in Table 2.

Table 2. Summary of annual benefits and costs hospital executive council length of stay reduction programs 1997-2012.

\begin{tabular}{|c|c|}
\hline \multicolumn{2}{|l|}{ Annual Benefits-15 Years } \\
\hline - Total Adult Medicine Patient Days Saved & $\$ 18,221,400$ \\
\hline - $\quad$ (30,369 Days at $\$ 600$ per Patient Day) & \\
\hline - Total Adult Surgery Patient Days Saved & $\$ 13,011,500$ \\
\hline - $\quad(26,023$ Days at $\$ 500$ per Patient Day) & \\
\hline - Total Patient Days Saved & $\$ 31,232,900$ \\
\hline • $\quad$ (56,392 Days) & \\
\hline - Discharges to Long Term Care & \\
\hline - Total Adult Medicine Patient Days Saved & $\$ 7,588,800$ \\
\hline - $\quad(12,648$ Days at $\$ 600$ per Patient Day) & \\
\hline - Total Adult Surgery Patient Days Saved & $\$ 4,859,500$ \\
\hline - (9719 Days at $\$ 500$ per Patient Day) & \\
\hline - Total Patient Days Saved & $\$ 12,448,300$ \\
\hline - $\quad$ (22,367 Days) & \\
\hline \multicolumn{2}{|l|}{ Annual Costs-15 Years } \\
\hline \multicolumn{2}{|l|}{ Severity Adjusted Length of Stay Data } \\
\hline - Hospital Executive Council (1440 Hours - 15 Years) & $\$ 115,200$ \\
\hline - Syracuse Hospitals (9000 Hours - 15 Years) & $\$ 900,000$ \\
\hline - Total & $\$ 1,015,200$ \\
\hline \multicolumn{2}{|l|}{ Difficult to Place Program } \\
\hline - Hospital Executive Council (2160 Hours - 15 Years) & $\$ 172,800$ \\
\hline - Syracuse Hospitals (8640 Hours - 15 Years) & $\$ 864,000$ \\
\hline - Total & $\$ 1,036,800$ \\
\hline \multicolumn{2}{|l|}{ Subacute Programs } \\
\hline - Hospital Executive Council (2200 Hours - 15 Years) & $\$ 220,000$ \\
\hline - Syracuse Hospitals (2200 Hours - 15 Years) & $\$ 176,000$ \\
\hline - Program Development Funds & $\$ 1,696,025$ \\
\hline - Total & $\$ 2,092,025$ \\
\hline \multicolumn{2}{|l|}{ Benefits Versus Costs } \\
\hline - All Patients & \\
\hline - Benefits & $\$ 31,232,900$ \\
\hline - Costs & $\$ 4,144,025$ \\
\hline \multicolumn{2}{|l|}{ Benefits Versus Costs } \\
\hline - Discharges to Long Term Care & \\
\hline - Benefits & $\$ 12,448,300$ \\
\hline - Costs & $\$ 3,128,825$ \\
\hline
\end{tabular}




\section{Discussion}

This study reviewed the economic and financial impact of community wide programs for improving the efficiency of utilization and outcomes in the metropolitan area of Syracuse, New York. It focused on comparison of the financial benefits with the expenses of these programs.

The study suggested that the financial benefits of reducing hospital lengths of stay through both types of initiatives were considerable. These estimates involved conservative assumptions about the numbers of inpatient days that could be eliminated, as well as the costs of those days.

Even at the conservative costs of patient days late in hospital stays, approximately between $\$ 12,000,000$ and $\$ 31,000,000$ were saved over the 15-year history of the length of stay reduction project. A reduction of half of this total, because of the need to maintain basic levels of hospital core services, would equal approximately $\$ 829,000$ to $\$ 2,082,000$ in annual benefits compared with about $\$ 208,000$ - \$276,000 in annual expenses.

Similarly, at the conservative number of complications eliminated through actual interventions and at the expenses of late stay patient days, between $\$ 1,622,400$ and $\$ 3,600,000$ were saved through the complications program. This would amount to a savings of approximately $\$ 400,000$ - $\$ 900,000$ in annual benefits, compared with $\$ 184,800$ in annual costs.

\section{Conclusions}

The study demonstrated that considerable financial benefits could be gained from community wide efforts to improve the efficiency of hospital utilization and outcomes. These benefits were demonstrated even under numerous conservative assumptions with respect to both types of initiatives.

The favorable economics generated by these programs in Syracuse were produced, in part, by the sharing of program costs for data development and coordination through the Hospital Executive Council. Duplication of these costs among the hospitals would have reduced the financial advantages of these programs. The sharing of these costs created the opportunity for collaborative efforts among the hospitals and for comparison of the impact of program initiatives, as well as for saving community wide resources in the process.

\section{References}

[1] Dentzler, S. (2011) Urgent Measures for an Old Problem. Health Affairs, 30, 1626.

[2] Auerbach, D.L. and Kellerman, A.L. (2011) A Decade of Health Care Cost Growth Has Wiped out Real Income Gains for an Average US Family. Health Affairs, 30, 1630-1636. http://dx.doi.org/10.1377/hlthaff.2011.0585

[3] Skinner, J., Chandra, A., Goodman, D. and Fisher, E.S. (2009) The Elusive Connection between Health Care Spending and Quality. Health Affairs, 28, w119-w123. http://dx.doi.org/10.1377/hlthaff.28.1.w119

[4] Farrell, D., Kocher, B., Laboissiere, P. and Parker, S. (2008) Accounting for the Cost of US Health Care: A New Look at Why Americans Spend More. McKinsey Global Institute, Washington DC.

[5] Marcus, A. (2009) Bending the Curve: The Twists and Turns. Health Affairs, 28, 1256-1258. http://dx.doi.org/10.1377/hlthaff.28.5.1256

[6] Martin, A.B., Hartman, M., Whittle, L. and Catlin, A. (2014) National Health Spending in 2012: Rate of Health Spending Growth Remains Low for the Fourth Consecutive Year. Health Affairs, 33, 67-77. http://dx.doi.org/10.1377/hlthaff.2013.1254

[7] Levey, N. (2012) The Election and the Nation's Fiscal Plight Aim the Spotlight Again on Medicare. Health Affairs, 31, 2163-2174. http://dx.doi.org/10.1377/hlthaff.2012.0949

[8] Aaron, H.J. and Ginsburg, P.B. (2009) Is Health Care Spending Excessive? If So, What Can We Do about It? Health Affairs, 28, 1260-1275. http://dx.doi.org/10.1377/hlthaff.28.5.1260

[9] Ayanian, J.Z. and Van der Wees, P.J. (2012) Tackling Rising Health Care Costs in Massachusetts. New England Journal of Medicine, 367, 790-793. http://dx.doi.org/10.1056/NEJMp1208710

[10] Hoonhout, L.H., deBruijne, M.C., Wagner, C., Zegers, M., Waaijman, R., Spreeuwenberg, P., Asscheman, H., van der Wal, G. and van Tulder, M.W. (2009) Direct Medical Costs of Adverse Events in Dutch Hospitals. BMC Health Services Research, 9, 27. http://dx.doi.org/10.1186/1472-6963-9-27

[11] Fuller, R.L., McCullough, E.C., Bao, M.Z. and Averill, R.F. (2009) Estimating the Costs of Potentially Preventable Hospital Complications. Health Care Financing Review, 30, 17-32.

[12] Fisher, E.S., Shortell, S.M., Kriendler, S.A., Van Citters, A.D. and Larson, B.K. (2012) A Framework for Evaluating 
the Formation, Implementation, and Accountable Care Organizations. Health Affairs, 31, 2368-2378. http://dx.doi.org/10.1377/hlthaff.2012.0544

[13] Calikoglu, S., Murray, R. and Feeney, D. (2012) Hospital Pay for Performance Programs in Maryland Produced Strong Results-Including Reduced Hospital Acquired Conditions. Health Affairs, 31, 2649-2657. http://dx.doi.org/10.1377/hlthaff.2012.0357

[14] Averill, R.F., McCullough, E.C., Hughes, J.S., Goldfield, N.I., Vertrees, J.C. and Fuller, R.L. (2009) Redesigning the Medicare Inpatient PPS to Reduce Payments for Hospitals with High Readmission Rates. Heath Care Financing Review, 30, 1-15.

[15] Rau, J. (2012) Medicare to Penalize 2211 Hospitals for Excess Readmissions. Kaiser Health News, Sacramento.

[16] McKinney, M. (2012) No Consensus: Healthcare Systems Slam NQF over Support of Readmissions Measure. Modern Healthcare, 42, 6-7, 12.

[17] Lagoe, R., Noetscher, C., Markle, A. and Johnson, P. (2010) Community-Wide Programs to Support Hospital Discharges to Nursing Homes. Topics in Advanced Practice Nursing eJournal, 10.

[18] Evans, M. (2012) The Early Returns on Accountable Care. Modern Healthcare, 42, S1-S5.

[19] Lagoe, R., Pasinski, T., Kronenberg, P., Quinn, T. and Schaengold, P. (2006) Linking Health Services at the Community Level. Canada Healthcare Quarterly, 9, 60-65. http://dx.doi.org/10.12927/hcq..18229

[20] Lagoe, R.J. and Westert, G.P. (2010) Evaluation of Hospital Inpatient Complications: A Planning Approach. BMC Health Services Research, 10, 200. http://dx.doi.org/10.1186/1472-6963-10-200

[21] Lagoe, R.J., Nanno, D.S. and Luziani, M.E. (2012) Quantitative Tools for Addressing Hospital Readmissions. BMC Research Notes, 5, 620. http://dx.doi.org/10.1186/1756-005-5-620

[22] Lagoe, R.J., Dauley Altwarg, J. and Noetscher, C.M. (2005) Development and Implementation of a Community-Wide Infusion Therapy Program by Hospitals and Nursing Homes in Syracuse, New York. Journal of Infusion Nursing, 28, 1-7. http://dx.doi.org/10.1097/00129804-200509000-00003

[23] Averill, R.F., Goldfield, N.I. and Muldoon, J. (2002) A Closer Look at All Patients Refined DRGs. Journal of AHIMA, 10, 46-50.

[24] Hughes, J.S., Averill, R.F. and Goldfield, N.J. (2006) Identifying Potentially Preventable Complications Using a Present on Admission Indicator. Health Care Financing Review, 27, 63-82.

[25] Massachusetts Hospital Association (2010) Position Concerning Potentially Preventable Complications. Massachusetts Hospital Association, Boston. 